THIS IS AN EARLIER VERSION OF THE MANUSCRIPT. FOR THE FINAL

ONLINE PUBLISHED VERSION OF THE MANUSCRIPT PLESASE

REFER TO:

Pellicer-Sánchez, A. (2015). Incidental learning of L2 collocations: A classroom study. Language Teaching Research. Advance online publication: DOI: $10.1177 / 1362168815618428$.

\title{
Learning $\mathrm{L} 2$ collocations incidentally from reading
}

\author{
Ana Pellicer-Sánchez \\ University of Nottingham
}

\begin{abstract}
Previous studies have shown that intentional learning through explicit instruction is effective for the acquisition of collocations in a second language (L2) (e.g. Peters, 2014, 2015), but relatively little is known about the effectiveness of incidental approaches for the acquisition of L2 collocations. The present study examined the incidental acquisition of collocational knowledge when learners encounter adjective-pseudoword collocations while reading. Forty-one L2 learners read a story containing six target collocations in a classroom setting. One week after the reading they were interviewed about their knowledge of the form, meaning and collocation of the target items (at recall and recognition levels). Participants were randomly assigned to one of two experimental groups, i.e. the 4-repetition group and the 8-repetition group. Results showed that collocational knowledge can be learnt incidentally from reading; that it is learnt at a similar rate to other lexical components such as form and meaning of individual words; and that the frequency manipulation in this study did not seem to have a significant effect on the acquisition of any of the aspects examined.
\end{abstract}

\section{Keywords}

Incidental learning, collocations, vocabulary, multi-word units, reading 


\section{Introduction}

Vocabulary is an essential component of language and it has a tendency to occur in multiword units (Schmitt, 2010), i.e. lexical units which consist of more than one word (McCarthy, 1990). However, despite the importance of mastering knowledge of different types of multi-word units for achieving high levels of language proficiency and fluency in a second language (L2) (e.g. Boers, Eyckmans, Kappel, Stengers, Demecheleer, 2006; Granger, 1998; Stengers, Boers, Housen, Eyckmans, 2011), research into the teaching and learning of multi-word units is still scarce.

Vocabulary teaching traditionally tended to focus on individual words (Schmitt, 2010) and consequently, vocabulary learning studies also focused on examining the best approaches to teach and learn single words. However, vocabulary instruction research has recently started to examine the acquisition of lexical items beyond the single word, and collocation has been one of the types of multi-word units examined. Mackin (1978) already noted that learners of English could learn collocations from repeated exposures in reading or by explicit teaching in the classroom. Recent studies on the learning of collocations have indeed been conducted around these two main approaches: explicit/intentional learning and incidental learning. Intentional learning is the learning that occurs when there is a particular intention to learn a set of items (Nation, 2001), whereas incidental vocabulary learning is the learning that occurs when learners' attention is focused on understanding messages without a particular intention to learn a set of words (Ellis, 1999). The majority of empirical studies on the acquisition of collocations have examined intentional learning through explicit teaching/learning (e.g. Boers, Demecheleer, Coxhead, \& Webb, 2014; Chan \& Liou, 2005; Lindstromberg \& Boers, 2008; Sun \& Wang, 2003; Peters, 2014, 2015; Webb \& Kagimoto, 2009, 2011), and have shown that several explicit teaching activities lead to the acquisition of L2 collocations (e.g. cloze tasks, multiple-choice tasks, dictionary use). However, the 
impossibility to teach all collocations by means of explicit vocabulary activities, due to the often limited classroom time, leads to the need to explore other incidental approaches to the learning of collocations. Very few studies have examined the incidental acquisition of collocations and they have yielded somewhat conflicting results. Webb, Newton, and Chang (2013) showed that reading while listening seemed to be an effective ${ }^{1}$ method for learning L2 collocations, whereas Szudarski (2012) found that reading only did not lead to much learning of collocations. With the limited empirical evidence available so far, little is still known about how, and if, collocations can be learned incidentally from reading.

\section{Background}

\section{Knowledge of L2 collocations}

Collocation has been identified as one of the many types of multi-word units (Wray, 2002). A distinction has been made between two main approaches to the identification of collocation, i.e. the phraseological approach and the frequency-based approach. The phraseological approach, with proponents like Cowie (1994) and Howarth (1998), identifies collocations based on semantic principles, whereas the frequency-based approach, with proponents like Halliday (1961) and Sinclair (1991), identifies collocations based on the strength of co-occurrence of two lexical items. These two approaches have sometimes been combined in definitions like the one provided by Nation (2001) in which collocations are seen as "a group of words that belong together, either because they commonly occur together $(\ldots)$, or because the meaning of the group is not obvious from the meaning of the parts" (p. 317). Despite the different definitions of collocations, the most common definition is the frequent co-occurrence of two (or more) words (e.g. Lewis, 2000; Nesselhauf, 2005). In this frequency-based approach collocation refers to "the relationship a lexical item has with items that appear with greater than 
random probability in its (textual) context" (Hoey, 1991, p. 7) and this is the type of collocations that will be examined in this study. Knowledge of collocations is one of the key components of the use of a word and "knowing a word involves knowing what words it typically occurs with" (Nation, 2001, p.56).

Previous studies have suggested that L2 learners' knowledge of multi-word units lags behind their knowledge of single words (e.g. Bahns \& Eldaw, 1993) and that, even when they produce multi-word units, they tend to overuse certain types that they know very well (e.g. Foster, 2001; Granger, 1998) and their usage is sometimes inappropriate (e.g. Nesselhauf, 2003, 2005). Regarding collocations, some studies have shown that learners tend to produce fewer collocations than native speakers in oral tasks (e.g. Serrano, Stengers, \& Housen, 2015) and in writing (e.g. Laufer \& Waldman, 2011), even at the more advanced levels of proficiency. "This suggests that the difficulty learners have is not only that of learning which words go together, but also learning how to employ the chunks they know" (Schmitt, 2010, p. 144). These difficulties have not only been shown in the production of collocations, but also in their processing. Even advanced learners of English seem to have poorer intuitions than native speakers regarding the frequency of collocations and seem to be slower at processing them (Siyanova \& Schmitt, 2008; Siyanova-Chanturia \& Spina, in press). This has led to the general impression that collocations, and other multi-word units, are particularly problematic for L2 learners and are more difficult to learn but, as Schmitt (2010) notes, research has only partially supported this initial impression. Some other studies have in fact shown that learners' use of collocations does not significantly differ from native speakers' use (e.g. Siyanova \& Schmitt, 2008).

\section{Explicit teaching of collocations}


Previous research has shown that several types of explicit teaching activities can improve learners' knowledge of collocations. One of the types of activities previously investigated has been the use of corpus tools. Chan and Liou (2005) examined the potential of a bilingual concordancer on the learning of verb-noun collocations. The Chinese EFL learners in their study completed several online activities, some of which required them to use a concordancer and some others did not. Results showed that there was a significant improvement of collocational knowledge after completing the activities and that the concordancing approach led to higher gains in the immediate post-test. The concordancer has also been found to be particularly effective when used with an inductive approach, suggesting that it provides effective discovery learning possibilities (Sun \& Wang, 2003).

Another type of explicit activity that has been shown to positively contribute to the learning of collocations is dictionary use. The L2 learners in Laufer's (2011) study were given a set of sentences containing verb-noun collocations whose verb was missing, and they were asked to fill the missing verb with dictionary assistance. Results showed that the use of dictionary significantly increased collocational knowledge for the intermediate learners. However, the study also showed that sometimes the look ups resulted in the use of the wrong collocations and other times learners were not aware that the collocation was unfamiliar to them and did not seek dictionary help. This led her to conclude that awareness of collocations should be supplemented with word-focused instruction.

Boers, Demecheeler, et al. (2014) compared the effectiveness of three verb-noun matching exercises which made learners work with the components of the collocations separately (i.e. connecting the two parts, inserting the verb, underlining the verb) with activities in which the verb-noun collocation was presented as a whole (i.e. inserting the whole collocation). Results showed that all types of exercise formats only led to minimal gains in knowledge of collocations and that there was no difference between the two 
types of exercises. Not only did Webb and Kagimoto (2009) find that both productive tasks (i.e. a cloze task) and receptive tasks (i.e. reading and memorizing) improved learners' collocational knowledge but that both types of tasks seemed to be equally beneficial, with productive tasks being more effective for learners of higher proficiency and receptive tasks for learners of lower level.

The effect of tasks which promote the noticing of form and sound patterns has been investigated in several studies. Studies have shown the effectiveness of tasks involving several types of phonemic repetition, i.e. alliteration (e.g. Lindstromberg \& Boers, 2008a), and assonance (e.g. Lindstromberg \& Boers, 2008b).

Laufer and Girsai (2008) compared the effectiveness of a meaning-focused instruction (i.e. reading a text and completing two communicative tasks) with two other focus-onform approaches (i.e. reading the same text and completing text-based vocabulary tasks vs. reading the text and completing text-based translation tasks) for the learning of single words and verb-noun collocations. Results showed that the two focus-on-form groups led to the acquisition of collocations, whereas the meaning-focused instruction group learned almost no vocabulary. The contrastive analysis and translation group outperformed the other two groups in all tests.

Comparing the acquisition of single words and collocations, Peters (2014) found that explicit activities on verb-noun collocations were effective for establishing the initialform meaning connections for both single words and collocations, but that the recall of single words was higher, suggesting that collocations were more difficult to learn than single words. With a different type of verb-noun collocations, similar to the ones used in the present study, Kasahara $(2010,2011)$ examined learners' acquisition of unknown single words and known-and-unknown collocations from intentional vocabulary activities and found that learning a new word on its own was more difficult than learning a new 
word in a two-word combination. The known component of the collocation helped learners to learn the unknown component of the collocations.

This learning accruing from explicit activities appears to be affected by several intralexical and interlexical factors: the number of collocates per node word (with higher number of collocates leading to better learning of collocations than lower number of collocates), synonymy (with higher number of synonyms having a negative effect on the learning of collocations) (Webb \& Kagimoto, 2011); congruency (with congruent collocations being easier to recall than incongruent ones) (Nesselhauf, 2003) and collocate-node relationship (with adjective-noun collocations being easier to recall than verb-noun collocations) (Peters, 2015).

\section{Incidental learning of L2 collocations}

The majority of studies on incidental vocabulary learning have focused on the acquisition of new words from reading. Research studies in this area have shown that, although with modest gains, new words can be acquired incidentally from reading in a first language (L1) (e.g. Freebody \& Anderson, 1983; Nagy, Herman, \& Anderson, 1985; Saragi, Nation, \& Meister, 1978) and in an L2 context (e.g. Day, Omura, \& Hiramatsu, 1991; Horst, 2005; Zahar, Cobb, \& Spada, 2001) and that several components, other than meaning, can be acquired from reading (e.g. Brown, Waring, \& Donkaewbua, 2008; Horst, Cobb, \& Meara, 1998; Pellicer-Sánchez, 2015; Pellicer-Sánchez \& Schmitt, 2010; Pigada \& Schmitt, 2006; Rott, 1999; Waring \& Takaki, 2003; Webb, 2005, 2007a, 2007b), with different degrees of certainty of that knowledge (Pellicer-Sánchez, 2015; Wesche \& Paribakht, 2000).

However, only recently have researchers started to examine the effectiveness of reading for the acquisition of lexical items beyond the single word. Webb, Newton, and Chang (2013) explored the effectiveness of reading while listening for the incidental acquisition 
of collocations. Their EFL learners simultaneously read and listened to a modified graded reader which contained 18 verb-noun collocations. Participants read one of four versions of a graded reader, varying in the number of times the target collocations appeared, i.e. 1, $5,10,15$. Receptive knowledge of the form of the collocations was tested in a pre-test. Immediately after the treatment session participants completed four tests measuring their receptive and productive knowledge of the form and meaning of the collocations. Results showed a significant increase in learners' receptive knowledge of the form of the target collocations from the pre- to post-test in the four versions $(27 \%, 33 \%, 55 \%$, and $76 \%$ of the unknown items respectively). Results also showed gains in the other three measures (i.e. productive knowledge of form, productive knowledge of meaning, receptive knowledge of meaning). However, as noted by the authors, results from these three measures need to be interpreted with caution because of the lack of a pre-test of learners' productive knowledge of these three components of lexical knowledge. What can be interpreted with certainty though, is the higher scores obtained in the receptive measures when compared to productive tests.

Szudarski (2012) compared the effectiveness of reading only vs. reading plus treatments for the acquisition of delexical verb-noun collocations (e.g. take a photo). His EFL learners in the reading only and the reading plus groups were exposed to the target collocations in a weekly 45-minute treatment session during three consecutive weeks. Both groups were exposed to the target collocations through reading texts (with each collocation repeated six times), and the participants in the reading plus group were also asked to complete explicit vocabulary activities focusing on collocational patterns. Results showed that the reading only treatment led to a significant improvement in their collocational knowledge in the test of verb form recall (1.4 collocations learnt on average; $14 \%$ of the ten target collocations) and in the test of verb form recognition (1.3 collocations learnt on average; $13 \%$ of the ten target collocations) but not in the test of 
collocation form recall. However, this small improvement was not significantly different from the improvement experienced by the control group, which led him to conclude that the reading only condition did not lead to much improvement. Similarly, in a later study Szudarski and Carter (2014) examined the effectiveness of reading only (input flood condition) and reading with target words underlined (input enhancement condition) for the acquisition of verb-noun and adjective-noun collocations and found that the input flood condition did not appear to enhance learners' knowledge.

Although with a focus on the investigation of implicit and explicit knowledge of collocations, Sonbul and Schmitt (2013) compared the effect of reading and reading plus treatments on the learning of adjective-noun collocations. They examined three learning conditions: the enriched condition (i.e. reading a text with certain target collocations embedded three times); the enhanced condition (i.e. reading a text with embedded target collocations made salient with red, bold font); and the decontextualized condition (i.e. explicit teaching of target collocations). Results of explicit (i.e. form recall and recognition tasks) post-tests suggested that the reading only condition, i.e. the enriched condition, led to delayed recall gains of 27 percentage points and to delayed recognition gains of 21 percentage points for L2 participants. When the target items were made salient, i.e. the enhanced condition, gains were significantly higher (form recall $=37$ percentage points; form recognition $=32$ percentage points).

\section{The effect of frequency of exposure on incidental learning}

An important concern in incidental vocabulary acquisition research has been the role of frequency of exposure. In the L1 context, Saragi, Nation, and Meister (1978) found that new words needed to be met around 10 times for considerable learning to occur. In the L2 context, the minimum number of occurrences for stronger gains has varied from six occurrences (e.g. Rott, 1999), to eight (e.g. Horst, Cobb, \& Meara, 1998), and 10+ 
(Nation \& Wang, 1999; Pigada \& Schmitt, 2006; Pellicer-Sánchez \& Schmitt, 2010; Webb, 2007b). Results from these studies have led researchers to conclude that for considerable learning of new words from reading to take place, words need to be encountered around 8-10 times.

However, very few studies have looked at the effect of frequency on the learning of collocations. In her examination of the effect of explicit teaching activities, Peters (2014) compared the learning of items with 1, 3, and 5 exposures, and found that there was a large repetition effect (difference between 1 and 5 times) and that this effect seemed to be durable. Only a few studies have looked at the effect of repetition on the incidental learning of collocations from reading and studies have yielded conflicting results. Durrant and Schmitt's study (2010) highlighted the importance of repetition in establishing initial collocation memory traces. In a laboratory setting, their L2 speakers of English were exposed to adjective-noun combinations in conditions which manipulated the frequency of exposure of those items: the first group was exposed to the target collocations once in a sentence context; the second group was exposed to target collocations twice in the same sentence context (i.e. verbatim repetition); and the third group was exposed to the target collocations twice in two different sentences (i.e. varied repetition). Results showed that both repetition conditions showed better levels of recall than the single exposure group, with verbatim repetition being slightly more effective.

The EFL learners in Webb, Newton, and Chang's (2013) study read and listened to one of four versions of a modified graded reader, which varied in the number of encounters of the target collocations (i.e. 1, 5, 10, 15 encounters). Results showed that the number of encounters had a positive effect on learning. The 15-exposure group had significantly higher gains than any of the other groups but significant differences were also found between the five and ten encounter groups and the control group, which led them to 
conclude that five or more encounters may be necessary to learn the form of collocations incidentally.

However, Szudarski and Carter (2014), in their comparison of input flood and input enhancement conditions, compared the acquisition of collocations appearing six times vs. those appearing 12 times in the texts and found that more encounters did not necessarily lead to better results at all levels of collocational competence.

\section{Aims and research questions}

With the little empirical evidence available the effectiveness of reading for the incidental learning of L2 collocations is still unclear. Some of the studies reviewed in the previous section showed the effectiveness of reading for the incidental learning of L2 collocations (e.g. Sonbul \& Schmitt, 2013; Webb, Newton, \& Chang, 2013), whereas others questioned this effectiveness (e.g. Szudarski, 2012). Besides, the reading treatment in Webb, Newton, and Chang (2013) was supported by audio which could have led to greater gains. Most importantly, these previous studies used real collocations as their target collocations. Although having a higher ecological validity, the use of real collocations makes it difficult to control for prior knowledge of the collocation and of the individual components, particularly with transparent collocations. In order to overcome this limitation and eliminate the need to use pre-tests, Webb, Newton, and Chang (2013) suggested the use of pseudowords.

In addition, the multifarious nature of collocations (i.e. differing in the relationship between the node and the collocate, e.g. adjective-noun, verb-noun; and in the level of transparency, e.g. with more transparent collocations like pay cash and more opaque ones like pay attention) implies that results of a study with a certain type of collocation may not be generalizable to the learning and teaching of other types of collocations, further justifying the need for more research in this area. 
Another component of vocabulary knowledge examined in this study was the degree of certainty of responses. Subjective certainty ratings have been used in grammar research as a way of distinguishing between conscious and unconscious knowledge (Rebuschat, 2013). In vocabulary research Wesche and Paribakht (2000) found different levels of certainty in participants' knowledge of target words appearing in text-based vocabulary activities. Pellicer-Sánchez (2015), in her investigation of vocabulary learning from reading, found that the recall aspect examined (i.e. meaning recall) was not only the most difficult to acquire but it was also the aspect with the lowest degree of certainty for both L1 and L2 participants. No previous studies have investigated this component in the acquisition of collocations.

In order to address these issues, the present study explored the acquisition of L2 collocational knowledge from reading in a classroom context. Following Webb, Newton and Chang's (2016) recommendation, collocations containing a pseudoword were used. The study attempted to examine whether learners can acquire information about collocates when encountering novel words in a text or whether they would focus solely on the unknown items. The following research questions were therefore addressed:

- Can intermediate L2 learners acquire knowledge of the form and meaning of novel words and collocational knowledge regarding those novel words incidentally from reading? Which aspects are easier or more difficult to acquire?

- How certain are L2 learners of the knowledge of the form and meaning of novel words and of collocational knowledge regarding those novel words?

- Does frequency of exposure have an effect on the incidental acquisition of collocational knowledge?

Participants read a story containing adjective-pseudoword collocations in a classroom context and were then individually interviewed about their receptive and productive 
knowledge of the form and meaning of the pseudoword and the composition of the adjective-pseudoword collocation. Based on previous research, it was hypothesized that learners would be successful in learning the form-meaning link of some of the target pseudowords; that knowledge of the form of the collocations would be significantly more difficult to acquire than other components of lexical mastery (i.e. form and meaning of pseudowords); and that frequency of exposure would have a significant effect on this learning.

\section{Methodology}

\section{Participants}

Forty-six L2 learners of English initially participated in this study. Data from five participants who had not appropriately followed the procedure were discarded. Data from 41 participants were included in the study (10 male; 31 female). Their ages ranged from 18 to 42 years old $(M=25.4 ; S D=6.6)$. The 41 participants were from diverse language backgrounds (i.e. Arabic, Chinese, French, Italian, Japanese, Persian, Polish, Russian, Spanish, and Turkish) and they had all recently moved to the UK to complete an English language course. This was the first time that participants were living in an Englishspeaking country. The length of stay in the UK ranged from 1 week to 9 months $(M=8.5$ weeks; $S D=8.1$ weeks). They had all recently started a language course at a language school in the UK. Based on their level upon arrival, they had all been placed in an intermediate level group. They were also asked to self-rate their skills in English in a language background questionnaire they completed at the beginning of the study. Thirtyseven participants rated their reading skills above 5 in a 10 -point scale $(M=5.8 ; S D=$ 1.2; Min = 5; $\operatorname{Max}=8$ ). There were four participants who had rated their reading skills below 5. However, their reading comprehension scores and their vocabulary test scores were in line with the rest of participants and they did not report having any particular 
difficulties when reading the text. The lower self-score was probably due to a more cautious self-reporting style. Using the same self-rating test, the advanced learners of English in Pellicer-Sánchez' (2015) study had a mean reading score of 9 (Min= 7; Max= 10). It was therefore hypothesized that a score of 6 would be appropriate for an intermediate group of learners. A one-sample Wilcoxon signed ranked test (data not normally distributed) was run to determine whether participants' self-reported reading scores were significantly different from a hypothesized median of 6 . Results showed that there was no significant difference between participants' reading scores and the hypothesized median score of $6(p=.263)$ and the null hypothesis was therefore retained. Participants were randomly assigned to one of the two treatment groups. A MannWhitney $U$ test revealed no significant difference in the self-reported reading scores of the two groups $(U=197, Z=-.36, p=.722)$.

\section{Reading Materials}

The difficulty of finding enough collocations in written texts makes researching incidental learning of collocations from reading particularly problematic (Webb, Newton, \& Chang, 2013). It was therefore decided to use a modified text which would meet the needs of the study. The story had been specifically written for Pellicer-Sánchez' (2015) study ${ }^{2}$ and was then modified for the purposes of the present study. Two versions of the story were created. In Version A the adjective-pseudoword collocations were repeated eight times throughout the story (length: 2333 words). In Version B the pseudowords were repeated eight times throughout the story but their collocational adjectives only in four of those occasions (length: 2309 words) in order to recreate more closely authentic reading materials in which unknown words do not always appear with a collocate. The pseudowords in Version B did not appear with other adjective collocates. Of the words in the two versions of the story $98 \%$ belonged to the first 3,000 most frequent words in the 
British National Corpus (determined by Lextutor (Cobb, n.d.)). This was considered adequate percentage to indicate comprehension for participants of an intermediate level of proficiency, and the suitability of the text was later confirmed by the language tutor.

In order to avoid participants going back to previously read items, which would make it difficult to control for the effect of frequency of exposure, the story was divided into 25 paragraphs, each presented in a different A3 card. A True-False comprehension test containing 12 statements assessed participants' comprehension (from Pellicer-Sánchez, 2015).

\section{Target items}

The use of pseudowords as target stimuli has been a common procedure in vocabulary acquisition research with single words. Using pseudowords in studies examining the acquisition of collocations allows us to examine highly transparent collocations without having to pre-test previous knowledge of the collocation or of the constituent parts, or having to account for L1-L2 congruency, factors that are often very difficult to control for in acquisition research. Six adjective-pseudoword collocations were therefore inserted in the two versions of the story. The pseudowords, i.e. the second component of the target collocations, were taken from Pellicer-Sánchez' (2015): holter (workhouse), berrow (bowl), bancel (criminal), cambul (ring), twoser (noise), and soters (clothes). They all replaced high-frequency (1-3K from the BNC) concrete nouns in the text. They were carefully piloted by Pellicer-Sánchez' (2015) with both native and non-native participants, ensuring their suitability for the study and the similar degree of informativeness of the contexts in which target words were embedded. In order to select the first component, i.e. a real, high frequent adjective, a list of the most frequent collocates for each of the nouns replaced by the pseudowords was created. The most frequent collocate from the list which at the same time fitted in the story context was 
selected. All adjectives selected were within the twenty most frequent collocates of each noun and they all belonged to the first 2,000 most frequent words in the British National Corpus. This resulted in the following adjective-pseudoword collocations: old holter (old workhouse), small berrow (small bowl), dangerous bancel (dangerous criminal), magic cambul (magic ring), loud twoser (loud noise), and dirty soters (dirty clothes).

The target items were distributed throughout the story ensuring a balanced distribution. A maximum of two pseudowords appeared in any one paragraph.

\section{Measurement instruments}

A combination of paper and pencil and interview tests were used to measure participants' knowledge of the pseudoword and their collocates. The first three tests were taken from Pellicer-Sánchez (2015) and assessed learners' knowledge of the pseudowords. The first test assessed participants' ability to recognize the correct form of the target pseudowords among five options provided (the correct form, three distracters, and an "I don't know" option). The second test assessed participants' ability to recall the meaning of the pseudowords by asking them to say everything they knew about their meaning. The third test measured participants' ability to recognize the correct meaning among five options provided (the correct meaning, three distracters, and an "I don't know" option). The fourth test assessed participants' ability to recall the form of the collocation by asking them to say the adjective that frequently appeared with the pseudoword in the story. The last test assessed their ability to recognize the form of the collocation by asking them to select the right collocate among five options provided (the correct collocate, three distracters, and an "I don't know" option). The distracters had the same word class and were all semantically related to the content of the story, to make the discrimination only possible when learners could recognize the collocate. In all five tests participants were asked to indicate in a 1-4 scale how certain they were of their responses $(1=$ Very uncertain; 4= Very certain) (See Appendix for recognition tests). 


\section{Procedure}

The reading session took place in two intermediate English language classes during normal class time. At the beginning of the session participants completed a language background questionnaire and signed the consent forms. The reading activity was then explained by the researcher. Each learner was randomly given Version A or B of the story. Participants were not aware of the differences between the two versions. They were instructed to read individually for general comprehension and to read the A3 cards one by one, without going back to previously read sections of the story. After reading the story, learners completed the comprehension questions individually.

One week after the reading session they were individually interviewed about their knowledge of the pseudowords and collocates. The interviews took place over two days. The first (form recognition), the third (meaning recognition), and the fifth (collocation recognition) paper and pencil tests were completed individually, with the researcher present to make sure that each part was appropriately completed. The second test (meaning recall) and the fourth test (collocation recall) were conducted by means of a personal interview. The researcher showed participants an A3-size index card with each of the target items and asked them to say everything they knew about their meaning (in the second test) and to say the adjective that appeared frequently before the pseudoword in the story or any other word that they could recall as frequent collocates of the target pseudowords (in the fourth test). They were encouraged to say everything they could remember, even if they were not sure, but no other prompts were used. The whole procedure lasted around 30 minutes. The five vocabulary tests were scored using the same system $(1=$ correct response; $0=$ incorrect response). Partially correct responses were not scored. Given the small number of items in the study, a stricter approach to the scoring of responses was considered a more reliable indication of true vocabulary gains. 


\section{Results}

Results of the comprehension test showed adequate comprehension of the text $(M=11.20$, $S D=1.2, \operatorname{Min}=7 ; \operatorname{Max}=12)$

To answer the first research question, a non-parametric Friedman test (data not normally distributed) was conducted to examine participants' performance in the five post-tests (see Table 1). Results showed that there was a significant difference across the scores of the five tests of Group A (participants exposed to the adjective-pseudoword collocations eight times $)\left(\chi^{2}(5, \mathrm{n}=20)=66.78, p<.001\right)$. Post-hoc analyses with Wilcoxon signedrank tests were conducted with Bonferroni correction applied $(p<.005)$ and results showed that Group A participants' ability to recall the meaning of the pseudowords was significantly lower than their ability to recognize the form of the pseudowords $(Z=-3$. $86, p<.001, r=.86)$, their ability to recognize the meaning $(\mathrm{Z}=-3.56, p<.001, r=.79)$, and their ability to recognize the correct collocate $(\mathrm{Z}=-3.97, p<.001, r=.89)$. Similarly, participants' ability to recall the correct collocate of the pseudowords was significantly lower than their ability to recognize the form of the pseudoword $(\mathrm{Z}=-.3 .70, p<.001, r=$ $.83)$, their ability to recognize the meaning of the pseudoword $(\mathrm{Z}=-3.44, p=.001, r=$ $.77)$, and their ability to recognize the correct collocate $(\mathrm{Z}=-3.96, p<.001, r=.89)$. The effect sizes are large, according to Cohen's (1988) criteria and medium-large according to Plonsky and Oswald's (2014) recently suggested more conservative criteria.

Results of the Friedman test with scores of Group B (participants exposed to the pseudowords eight times and to the adjective-pseudoword collocation four times) also showed that there was a significant difference across the scores of the five tests $\left(\chi^{2}(5, n\right.$ $=21)=68.16, p<.001)$. Post-hoc analyses with Wilcoxon signed-rank tests were conducted with Bonferroni correction applied $(p<.005)$ and results showed that Group B participants' ability to recall the meaning of the pseudowords was significantly lower 
than their ability to recognize their form $(\mathrm{Z}=-3.75, p<.001, r=.82)$, their ability to recognize the meaning of the pseudowords $(\mathrm{Z}=-3.72, p<.001, r=.81)$, and their ability to recognize the correct collocate of the pseudoword $(\mathrm{Z}=-4.05, p<.001, r=.99)$. Participants' ability to recall the correct collocate was significantly lower than their ability to recognize the form of the pseudoword $(\mathrm{Z}=-3.75, p<.001, r=.82)$, their ability to recognize their meaning $(\mathrm{Z}=-3.76, p<.001, r=.82)$, and their ability to recognize the correct collocate $(\mathrm{Z}=-4.04, p<.001, r=.88)$, with large effect sizes according to Cohen's (1988) criteria and medium-large according to Plonsky and Oswald's (2014) criteria.

\section{[INSERT TABLE 1 HERE]}

Overall, as expected, recall aspects were significantly more difficult to acquire than recognition aspects for both groups. No significant differences were found among the three recognition aspects or the two recall aspects. Recalling the collocate of a word was not significantly more difficult than recalling the meaning of the new lexical items. Similarly, learners' ability to recognize the correct meaning of the pseudoword was not significantly better than the ability to recognize the correct collocate. Knowledge of the form of collocations does not seem to be significantly more difficult to acquire than knowledge of the form-meaning link of novel words. The comparison between meaning and collocation recognition scores should be treated with caution, since the difficulty of these tests depends on the distracters included.

The relationship between meaning of pseudowords and knowledge of the form of collocations was explored by means of non-parametric correlations. Results showed that there was a significant positive correlation between meaning and collocational knowledge (Table 2), with higher scores in the meaning recognition test being related to higher scores in the two collocation tests and with high meaning recall scores associated with 
high collocation recognition scores. The correlation coefficient was large according to Cohen's (1988) criteria and medium-large according to Plonsky and Oswald's (2014) criteria.

\section{[INSERT TABLE 2 HERE]}

To answer the second research question and to examine the certainty of participants' knowledge of the above reported word knowledge aspects, potential differences in participants' degree of certainty were first examined looking at the certainty of all the target items, regardless of whether they had been learnt or not. Results of a KruskalWallis test showed that there was a significant difference in certainty scores across the four aspects measured $\left(\chi^{2}(4)=10.18, p=.037\right)$ (see Table 3 ). Post-hoc comparisons conducted with Mann-Whitney tests (Bonferroni adjusted Alpha value $p<.005$ ) revealed that participants were significantly more certain of their ability to recognize the correct form of the collocation than of recognizing the correct form of the target item $(U=$ $5789.5, Z=-2.91, p=.004, \mathrm{r}=.19)$. Examining the certainty of only those words for which participants had shown accurate knowledge in the post-reading tests, results of Friedman test showed that there was a significant difference in certainty scores of the different vocabulary tests $\left(\chi^{2}(4)=10.47, p=.033\right)$. Post-hoc comparisons with Wilcoxon signed ranks tests (Bonferroni adjusted alpha value $p<.005$ ) showed that participants certainty of their ability to recognize the form of the collocation was significantly higher than their certainty of pseudoword form recognition $(Z=-4.18, p<.001)$, than their certainty of pseudoword meaning recognition $(Z=-7.42, p<.001)$, and than their certainty of collocation form recall $(Z=-5.01, p<.001)$. Participants' certainty of their ability to recognize the correct meaning of the pseudoword was also significantly higher than their ability to recognize the correct form of the pseudoword $(Z=-5.26, p<.001)$. Meaning recall was the component with the lowest degree of certainty. 


\section{[INSERT TABLE 3 HERE]}

In response to the first and second research questions, results of this study showed that intermediate L2 learners of English were able to acquire knowledge of the form-meaning link of the unknown pseudowords and of the form of the collocations of those unknown lexical items, with participants in both groups learning around $40.50 \%$ of the six items at the recognition level and around $10 \%$ at the recall level. Results also showed that recall aspects were more difficult to acquire than recognition aspects and that knowledge of the form of collocations does not seem to be more difficult to acquire incidentally than the other components examined. Results also suggested that overall, participants' certainty of their ability to recognize the correct form of the collocation was significantly higher that most of the other aspects examined.

In order to answer the third research question and determine whether frequency of exposure has an effect on the incidental acquisition of collocational knowledge, nonparametric Mann Whitney U tests between each of the measures for Group A and Group B were conducted. Results showed that there were no significant differences between the two groups in any of the post-reading tests (Form recognition: $U=207.50, \mathrm{Z}=-.07, p=$ $.95, r=.01$; Meaning recall: $U=199.50, \mathrm{Z}=-.31, p=.76, r=.05$; Meaning recognition: $U=209.00, \mathrm{Z}=-.027, p=.98, r=.004$; Collocation recall: $U=172.50, \mathrm{Z}=-1.11, p=$ $.27, r=.02$; Collocation recognition: $U=203.00, \mathrm{Z}=-.19, p=.85, r=.03$ ). The lack of difference between the acquisition of meaning and form was expected, due to the same number of exposures to the pseudowords in both groups. However, despite the different number of exposures to the collocates, results showed no significant differences in the acquisition of collocational knowledge by the two groups.

\section{Discussion}


In response to the first research question, results of this study support previous research demonstrating the effectiveness of reading for the incidental learning of the form and meaning of unknown single words (e.g. Brown, Waring, \& Donkaewbua, 2008; Horst, Cobb, \& Meara, 1998; Pellicer-Sánchez, 2015; Pellicer-Sánchez \& Schmitt, 2010; Pigada \& Schmitt, 2006; Rott, 1999; Waring \& Takaki, 2003; Webb, 2005, 2007a, 2007b). Results also indicate that reading can lead to the improvement of learners' knowledge of the form of collocations, with participants recalling on average $11 \%$ and recognizing $50.5 \%$ of the collocates. This supports and expands results of Webb, Newton and Chang (2013), suggesting that a reading only treatment can also lead to the acquisition of collocations. Although these two studies had different frequency groups, a comparison of the most similar frequency groups shows similar results, considering that they looked at different types of items. The $48 \%$ of collocations that participants in this study were able to recognize after eight exposures is similar to the $33 \%$ figure in the five exposures group in Webb, Newton, and Chang. Similarly, the 53\% of collocations that participants in this study were able to recognize after eight exposures is similar to the $55 \%$ of collocations recognized after ten exposures. Results are even more encouraging considering that Webb, Newton, and Chang had immediate post-test whereas the post-tests in this study were conducted one week after the treatment. The collocation recognition scores in this study are higher than those in Sonbul and Schmitt (2013) (21 percentage points) but the recall scores are lower (27 percentage points).

Results of this study contrast with those of Szudarski (2012) who found that the learning gains experienced by participants in the reading only condition were not significantly different from those experienced by the control group. The difference between the results of Szudarski's and this study might be due to the different type of collocations explored. Szudarski looked at verb-noun collocations which contained delexical verbs, which tend to be particularly challenging for L2 learners (Attenberg \& Granger, 2001). Another 
reason might lie in the fact that, as shown by Kasahara (2011), the nature of the collocations explored in the present study, i.e. known adjective-unknown noun, might have supported the learning process. It is important to note that this comparison of learning gains in different studies needs to be treated with caution due to the different number of target items in each of these studies and the differences in the length of the reading treatments.

Not surprisingly, results have also shown that receptive aspects of the form of collocations are more easily enhanced than recall aspects, in line with other single word studies (e.g. Brown et al., 2008; Pellicer-Sanchez, in-press; Pellicer-Sánchez \& Schmitt, 2010; Webb, 2005, 2007a, 2007b) and other collocation studies (e.g. Peters, 2015; Szudarski, 2012; Webb, Newton, \& Chang, 2013). Findings also suggest that receptive aspects of the form of collocations are not only easier to acquire than productive ones but learners are also more certain about this knowledge. Within the recognition components examined in this study, results have also shown that learners are more certain about their ability to recognize the correct collocate of a word than their ability to recognize the form or the meaning of a novel word, providing further evidence that acquiring knowledge of the form of a collocation may not be intrinsically more difficult than other components of lexical mastery.

These findings suggest that acquiring knowledge of the form of collocations at both the receptive and productive (recognition and recall) levels might not be significantly more difficult than other components of lexical mastery, in line with previous findings suggesting that knowledge of the composition of collocations seems to be acquired at a rate similar to that of meaning of single word items (e.g. Webb \& Kagimoto, 2009). When encountering new words in reading, L2 learners seem to pick information about the form, meaning and the collocates of unknown words with the same level of difficulty, provided that they encounter them sufficient times. Adult L2 learners can retain 
information about what words tend to co-occur together and any problems in their knowledge might be due to inadequate input (Durrant \& Schmitt, 2010). Collocations are more frequent in spoken discourse than in written discourse, and the amount of exposure to authentic spoken discourse that most EFL learners receive is often very limited (Shin \& Nation, 2008). The likelihood of encountering the same collocations several times in the same text is very small (Boers \& Lindstromberg, 2009; Boers, Demecheleer, et al., 2014) and collocations in EFL textbooks do not recur enough for the learner to consolidate collocational knowledge (Tsai, 2014). The difficulty in the acquisition of collocations might not therefore lie in their intrinsic nature but in the difficulty of encountering collocations sufficient times and in a relatively short period of time in the kind of spoken and written texts that learners are usually exposed to.

Contrary to the initial hypothesis, the frequency manipulation in this study (eight vs. four exposures) did not have a significant effect on the learning of the form of collocations. This might suggest that for a significant effect of frequency to occur in an only reading treatment, items need to appear more frequently. This is contrary to results of Webb, Newton and Chang (2013) who found significant differences between five and ten encounters in a reading while listening condition. However, this lack of effect of frequency is in line with other recent studies which have claimed that the effect of frequency is more complex than we thought and that other factors may determine the effect of frequency, both with the acquisition of single words (e.g. Laufer \& RozovskiRoitblat, 2014; Webb \& Chang, 2014) and with collocations (e.g. Szudarski \& Carter, 2014).

Knowing that the explicit teaching of collocations can be expanded and supported by learning outside the classroom or by classroom reading activities which do not necessarily exclusively focus on the acquisition of vocabulary has important pedagogical implications. These findings would support claims of the advocates of the Lexical 
Approach who believe that teachers should not spend time teaching lexical chunks but raising students' awareness of the importance of phraseology so that they are more inclined to attend to multi-word units outside the classroom and can learn them incidentally (Boers \& Lindstromberg, 2009). The results of this study have therefore suggested that this is possible. However this assumption is based on an analogy with L1 learning and, as Boers and Lindstromberg (2009) claim, lexical chunks occur relatively infrequently in the written or spoken discourse learners are exposed to and even when they occur, learners may fail to notice them in the input. They therefore suggest the use of techniques which could make learners notice and pay attention to those lexical chunks in the input, e.g. highlighting or glossing, suggesting what they call a 'semi-incidental acquisition' approach. They define this approach as acquisition that still happens as a byproduct of a meaning-oriented activity but in which materials are manipulated or designed to stimulate learners' paying attention to these items. If we want to ensure that learners are exposed to collocations, and other types of multi-word units, sufficient number of times to lead to a considerable uptake, materials should therefore be modified to ensure this repeated exposure. As Webb, Newton, and Chang (2013) propose, unless reading materials are designed to ensure sufficient exposure to collocations, the potential for learning the majority of collocations incidentally is small. Graded readers and reading texts in textbooks should therefore consider this as a key design principle so that we can maximize the potential of learning collocations incidentally both in and outside the classroom.

\section{Limitations and Future Directions}

An important limitation of the present study is the use of pseudowords as the nodes of the collocations, since the effect of using pseudowords is still unclear. Using collocations made up of unknown words or made up of a combination of known and unknown words might make learners focus on deriving the meaning of the unknown word than on 
learning the form of the collocation (Webb, Newton \& Chang, 2013). On the contrary, other researchers have suggested that having multi-word units made up of unknown words might make the words more noticeable and may result in greater learning (e.g. Boers \& Lindstromberg, 2009). In addition, as Kasahara (2011) showed, the known component of the collocation might have positively influenced the learning of the pseudoword. Future research should compare the incidental learning of collocations made up of unknown items with comparable collocations made up of known items.

The pseudowords in this study replaced high frequency words, as opposed to low frequency real words as it is the case in other studies. As Pellicer-Sánchez (2015) argued, results of the study are representative of those situations in which learners learn another L2 label for a concept for which they already have an L2 word, but not of those different learning contexts in which learners learn an L2 word for an L1 concept for which they do not have an L2 word yet.

In addition, the adjectives selected for the collocations were frequent collocates of the real nouns that the pseudowords replaced. The possible association in the learners' mental lexicon of the adjective and the substituted noun might have influenced post-test performance. This transfer of knowledge of the adjective-noun collocation to adjectivepseudoword might explain the strong correlation found between participants' performance on the word-meaning and the collocation tests. Future studies should be conducted with adjectives that are less frequent collocates of the real nouns substituted.

Another important limitation of the items used in the present study has to do with their semantic transparency. The collocations used in this study were very semantically transparent, once the meaning of the pseudoword had been guessed. The recall and recognition of the correct collocate might therefore be dependent to a certain extent on 
the learning of the pseudoword. Future research should look at the acquisition of collocations with different levels of transparency.

Regarding the measures used, it is important to note that being exposed to the meaning of the pseudowords in the third test, i.e. meaning recognition, might have influenced the responses in the two collocation tests, particularly in the collocation recognition test, although distracters were carefully designed to make them all possible candidates.

Although all participants in this study had been placed at an intermediate level in the school and there were not significant differences in the self-rated reading scores between the two experimental groups, the use of a more generalized measure of proficiency would have allowed for a more in depth investigation of the role of proficiency and vocabulary knowledge on the learning gains in the study.

\section{Conclusion}

The results of the present study suggest that knowledge of the form of collocations can be acquired incidentally from reading, and that it seems to be acquired at a rate similar to that of other components of lexical mastery, i.e. form and meaning of single words. This study, however, can only explain the acquisition of this particular type of two-word combinations. Given the multifarious nature of collocations, further research needs to be conducted with different types of collocations so that we can reach a clearer understanding of the effectiveness of reading for the incidental acquisition of collocations.

\section{Acknowledgements}

I would like to thank Elizabeth Stewart for her help with data collection.

\section{Declaration of conflicting interest}

The author declares that there is no conflict of interest.

\section{Notes}


${ }^{1}$ Effectiveness is understood in this paper as leading to significant learning gains.

${ }^{2}$ See Pellicer-Sánchez (2015) for a detailed explanation of reading materials, target items, and their piloting.

\section{References}

Altenberg, B. \& Granger, S. (2001). The grammatical and lexical patterning of make in native and non-native student writing. Applied Linguistics, 22, pp.173-195.

Bahns, J., \& Eldaw, M. (1993). Should we teach EFL students collocations? System, 21, $101-114$.

Boers, F., Demecheleer, M., Coxhead, A., \& Webb, S. (2014). Gauging the effects of exercises on verb-noun collocations. Language Teaching Research, 18(1), 54-74.

Boers, F., Eyckmans, J., Kappel, J., Stengers, H., \& Demecheleer, M. (2006). Formulaic sequences and perceived oral proficiency: Putting a lexical approach to the test. Language Teaching Research, 10, 245-261.

Boers, F., Eyckmans, J., \& Lindstromberg, S. (2014). The effect of discrimination task on L2 learners' recall of collocations and compounds. International Journal of Applied Linguistics, 24(3), 357-369.

Boers, F. \& Lindstromberg, S. (2009). Optimizing a lexical approach to instructed language acquisition. Palgrave Macmillan: Basingstoke, UK,

Brown, R., Waring, R., \& Donkaewbua, S. (2008). Incidental vocabulary acquisition from reading, reading-while-listening, and listening. Reading in a Foreign Language, 20, 136-63.

Chan, T. P., \& Liou, H. C. (2005).Effects of web-based concordancing instruction on EFL students' learning of verb-noun collocations. Computer Assisted Language Learning, 18, 231-251. 
Cohen, J. W. (1988). Statistical power analysis for the behavioural sciences $\left(2^{\text {nd }} \mathrm{edn}\right.$.). Hillsdale, NJ: Lawrence Erlbaum Associates.

Cowie, A. P. (1994). Phraseology. In R. E. Asher (Ed.), The Encyclopedia of Language and Linguistics (pp. 3168-3171). Oxford: Pergamon.

Day, R. R., Omura, C., \& Hiramatsu, M. (1991). Incidental EFL vocabulary learning and reading. Reading in a Foreign Language, 7, 541-551.

Durrant, P. \& Schmitt, N. (2010). Adult learners' retention of collocations from exposure. Second Language Research, 26(2), 163-188.

Ellis, R. (1999). Learning a second language through interaction. Amsterdam: John Benjamins.

Foster, P. (2001). Rules and routines: A consideration of their role in the task-based language production of native and non-native speakers. In M. Bygate, P. Skehan, \& M. Swain (Eds.), Researching pedagogic tasks: Second language learning, teaching, and testing (pp. 75-93). Harlow: Longman.

Freebody, P., \& Anderson, R. (1983). Effects of vocabulary difficulty, text cohesion, and schema availability on reading comprehension. Reading Research Quarterly, 18, 277294.

Granger, S. (1998). Prefabricated patterns in advanced EFL writing: Collocations and formulae. In Cowie, A. P. (ed.), Phraseology: Theory, Analysis, and Applications (pp.145-160). Oxford: Oxford University Press.

Halliday, M. A. K. (1961). Categories of the theory of grammar. Word, 17, 241-292.

Hoey, M. (1991). Patterns of lexis in text. Oxford: Oxford University Press.

Horst, M. (2005). Learning L2 vocabulary through extensive reading: A measurement study. The Canadian Modern Language Review, 61, 355-382.

Horst, M., Cobb, T., \& Meara, P. (1998). Beyond a clockwork orange: Acquiring second language vocabulary through reading. Reading in a Foreign Language, 11, 207-223. 
Howarth, P. (1998). Phraseology and second language proficiency. Applied Linguistics, 19(1), 24-44.

Kasahara, K. (2010). Are two words better than one for intentional vocabulary learning? Annual Review of English Language Education in Japan, 21, 111-120.

Kasahara, K. (2011). The effect of known-and-unknown word combinations on intentional vocabulary learning. System, 39, 491-499.

Laufer, B. (2011). The contribution of dictionary use to the production and retention of collocations in a second language. International Journal of Lexicography, 24(1), 2949.

Laufer, B. \& Girsai, N. (2008). Form-focused instruction in L2 vocabulary learning. Applied Linguistics, 29(4), 694-716.

Laufer, B. \& Rozovski-Roitblat, B. (2015). Retention of new words: Quantity of encounters, quality of task, and degree of knowledge. Language Teaching Research, 19(6), 687-711.

Laufer, B. \& Waldman, T. (2011). Verb-noun collocations in second language writing: A corpus analysis of learners' English. Language Learning, 61, 647-672.

Lewis, M. (2000). Teaching collocation: further developments in the lexical approach. Hove: Language Teaching Publications.

Lindstromberg, S. \& Boers F. (2008a). The mnemonic effect of noticing alliteration in lexical chunks. Applied Linguistics 29(2), 200-222.

Lindstromberg, S. \& Boers, F. (2008b). Phonemic repetition and the learning of lexical chunks: The power of assonance. System, 36, 423-436.

Mackin, R. (1978). On collocations: 'Words shall be known by the company they keep'. In P. Strevens (ed.), In honour of A. S. Hornby (pp. 149-165). Oxford: Oxford University Press.

McCarthy, M. (1990). Vocabulary. Oxford: Oxford University Press. 
Nagy, W., Herman, P., \& Anderson, R. (1985). Learning words from context. Reading Research Quarterly, 20, 233-253.

Nation, I. S. P. (2001). Learning Vocabulary in Another language. Cambridge: Cambridge University Press.

Nation, I. S. P., \& Wang, K. (1999).Graded readers and vocabulary. Reading in a Foreign Language, 12, 355-380.

Nesselhauf, N. (2003). The use of collocations by advanced learners of English and some implications for teaching. Applied Linguistics, 24(2), 223-242.

Nesselhauf, N. (2005). Collocations in a learner corpus. Amsterdam: John Benjamins.

Pellicer-Sánchez, A. (2015). Incidental L2 vocabulary acquisition from and while reading: An eye-tracking study. Studies in Second Language Acquisition, available on CJO2015. doi:10.1017/S0272263115000224.

Pellicer-Sánchez, A., \& Schmitt, N. (2010). Incidental Vocabulary Acquisition from an Authentic Novel: Do things fall apart? Reading in a Foreign Language, 22(1), 31-55.

Peters, E. (2014). The effects of repetition and time of post-test administration on EFL learners' form recall of single words and collocations. Language Teaching Research, 18(1), 75-94.

Peters, E. (2015). The learning burden of collocations: The role of interlexical and intralexical factors. Language Teaching Research, 1-26.

Pigada, M., \& Schmitt, N. (2006). Vocabulary acquisition from extensive reading: A case study. Reading in a Foreign Language, 18(1), 1-28.

Plonsky, L. \& Oswald, F. L. (2014). How big is "Big"? Interpreting effect sizes in L2 research. Language Learning, 64(4), 878-912.

Rebuschat, P. (2013). Measuring implicit and explicit knowledge in second language research. Language Learning, 63, 595-626.

Rott, S. (1999). The effect of exposure frequency on intermediate language learners' 
incidental vocabulary acquisition through reading. Studies in Second Language Acquisition, 21, 589-619.

Saragi, T., Nation, I. S. P., \& Meister, F. (1978). Vocabulary learning and reading. System, 6, 72-78.

Schmitt, N. (2010). Researching vocabulary: A vocabulary research manual. London: Palgrave Macmillan.

Serrano, R., Stengers, H., \& Housen, A. (2015). Acquisition of formulaic sequences in intensive and regular EFL programmes. Language Teaching Research, 19(1), 89106.

Shin, D., \& Nation, I. S. P. (2008). Beyond single words: The most frequent collocations in spoken English. ELT Journal, 64, 339-348.

Sinclair, J. (1991). Corpus, concordance, collocation: Describing English Language. Oxford: Oxford University Press.

Siyanova, A. \& Schmitt, N. (2008).L2 learner production and processing of collocation: A multi-study perspective. The Canadian Modern Language Review, 64(3), 429458.

Siyanova-Chanturia, A. \& Spina, S. (in press, 2015). Investigation of native speaker and second language learner intuition of collocation frequency. Language Learning, 65(3).

Sonbul. S. \& Schmitt, N. (2013). Explicit and Implicit lexical knowledge: Acquisition of collocations under different input conditions. Language Learning, 63(1), 121-159.

Stengers, H., Boers, F., Housen, A., \& Eyckmans, J. (2011). Formulaic sequences and L2 oral proficiency: Does the type of target language influence the association? International Review of Applied Linguistics in Language Teaching, 49, 321-343. 
Sun, Y. C., \& Wang, L. Y. (2003). Concordancers in the EFL classroom: Cognitive approaches and collocation difficulty. Computer Assisted Language Learning, 16, 83-94.

Szudarski, P. (2012). Effects of Meaning- and Formed-Focused instruction on the acquisition of verb-noun collocations in L2 English. Journal of Second Language Teaching and Research, 1(2), 3-37.

Szudarski, P. \& Carter, R. (2014). The role of input flood and input enhancement in EFL learners' acquisition of collocations. International Journal of Applied Linguistics, available on doi: 10.1111/ijal.12092.

Tsai, K. (2014). Profiling the collocation use in ELT textbooks and learner writing. Language Teaching Research, 1-18.

Waring, R., \& Takaki, M. (2003). At what rate do learners learn and retain new vocabulary from reading a graded reader? Reading in a Foreign Language, 15, 13063.

Webb, S. (2005). Receptive and productive vocabulary learning: The effect of reading and writing on word knowledge. Studies in Second Language Acquisition, 27(1), 3352.

Webb, S. (2007a). Learning word pairs and glossed sentences: The effects of a single context on vocabulary learning. Language Teaching Research, 11(1), 63-81.

Webb, S. (2007b). The effects of repetition on vocabulary knowledge. Applied Linguistics, 28, 46-65.

Webb, S. \& Chang, A. (2015). Second language vocabulary learning through extensive reading with audio support: How do frequency and distribution of occurrence affect learning? Language Teaching Research, 19(6), 667-686.

Webb, S. \& Kagimoto, E. (2009). The effects of vocabulary learning on collocation and meaning. TESOL Quarterly, 4(1), 55-76. 
Webb, S. \& Kagimoto, S. (2011). Learning Collocations: Do the number of collocates, position of the node word, and synonymy affect learning? Applied Linguistics, 32(3), 259-276.

Webb, S., Newton, J., \& Chang, A. (2013). Incidental learning of collocation. Language Learning, 63(1), 91-120.

Wesche, M. \& Paribakht, S. (2000). Reading-based exercises in second language vocabulary learning: An introspective study. Modern Language Journal, 84, 196213.

Wray, A. (2002). Formulaic language and the lexicon. Cambridge: Cambridge University Press.

Zahar, R., Cobb, T., \& Spada, N. (2001). Acquiring vocabulary through reading: Effect of frequency and contextual richness. Canadian Modern Language Review, 57(3), $541-572$. 


\section{Appendices}

\section{Test 1- Form recognition}

Choose the right spelling for the following six words that have appeared in the story (Only one is correct) and indicate in the scale on the right how certain you are of your response. Example:

a) ackol

b) acklon

c) hacklon

d) hackol

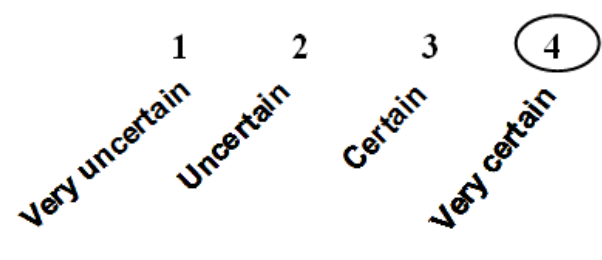

\begin{tabular}{|c|c|c|c|c|c|c|c|}
\hline 1. a) hotler & b) holter & c) houter & d) houler & 1 & 2 & 3 & 4 \\
\hline 2. a) twoser & b) twonse & c) twiser & d) twines & 1 & 2 & 3 & 4 \\
\hline 3. a) borreu & b) berrou & c) berrow & d) borrew & 1 & 2 & 3 & 4 \\
\hline 4. a) bancel & b) bansel & c) blancel & d) blansel & 1 & 2 & 3 & 4 \\
\hline 5. a) cambule & b) cambuel & c) cambeul & d) cambul & 1 & 2 & 3 & 4 \\
\hline 6. a) solers & b) soters & c) sorels & d) sorets & 1 & 2 & 3 & 4 \\
\hline
\end{tabular}

\section{Test 3-Meaning recognition}

Select one of the five options. Only one is the correct definition. If you don't know the meaning of the word, please select option " $e$ ". For each response indicate how certain you are of your response (1-4).

1) holter
a) basement
b) workhouse
c) prison
d) food hall
e) I don't know.

3) berrow
a) market
b) bowl
c) entrance
d) bottle
e) I don't know

2) twoser

4) bancel
a) story
a) orphan
b) punishment
b) prisoner
c) noise
c) worker
d) game
d) chief
e) I don't know
e) I don't know. 

a) picture
a) shoes
b) plate
b) clothes
c) window
c) dishes
d) ring
d) tools
e) I don't know.
e) I don't know.

\section{Test 5- Collocation recognition}

Try to fill the blanks with the word that you think appeared frequently in the story before the words in bold. Select one of the five options. Only one is the correct option. If you don't know the meaning of the word, please select option " $e$ ".

1) They lived in a/an holter
a) small
b) old
c) poor
d) dirty
e) I don't know.

2) They heard a/an twoser
a) big
b) huge
c) loud
d) bad
e) I don't know

3) They ate in a/an berrow
a) small
b) slight
c) tiny
d) little
e) I don't know

4) He was treated like a/an bancel
a) poor
b) serious
c) angry
d) dangerous
e) I don't know.

5) His mother gave him a/an cambul
a) secret
b) magic
c) old
d) lucky
e) I don't know.

6) The had to wear soters
a) old
b) dirty
c) small
d) poor
e) I don't know. 


\section{Tables}

Table 1

Post reading vocabulary test scores

\begin{tabular}{lcccc}
\hline & \multicolumn{2}{c}{ Group A } & \multicolumn{2}{c}{ Group B } \\
& $\mathrm{M}$ & $\mathrm{M}$ & $\mathrm{M}$ & $\mathrm{M}$ \\
& $\mathrm{N}$ items ${ }^{\mathrm{a}}$ & $\%$ & $\mathrm{~N}$ items & $\%$ \\
Form recognition & $2.95(1.43)$ & $49.17 \%$ & $2.81(1.69)$ & $46.83 \%$ \\
Meaning recall & $0.55(0.76)$ & $9.17 \%$ & $0.62(0.81)$ & $10.33 \%$ \\
Meaning recognition & $2.45(1.73)$ & $40.83 \%$ & $2.38(1.47)$ & $39.67 \%$ \\
Collocation recall & $0.90(1.37)$ & $15.00 \%$ & $0.43(0.68)$ & $7.17 \%$ \\
Collocation recognition & $3.20(1.70)$ & $53.33 \%$ & $2.90(1.09)$ & $48.33 \%$ \\
\hline Max=6 & & & &
\end{tabular}

Table 2

Non-parametric correlations between meaning and collocation components of lexical mastery

\begin{tabular}{|c|c|c|c|c|}
\hline & \multicolumn{2}{|c|}{ Collocation recall } & \multicolumn{2}{|c|}{ Collocation recognition } \\
\hline & $r_{\mathrm{s}}$ & Sig. (2-tailed) & $r_{\mathrm{s}}$ & Sig. (2-tailed) \\
\hline Meaning recognition & .452 & $.003 *$ & .571 & $.000 *$ \\
\hline Meaning recall & .122 & .245 & .528 & $.000 *$ \\
\hline
\end{tabular}

* Alpha level adjusted with Bonferroni correction to $p<.013$ 
Table 3

Degree of certainty scores

\begin{tabular}{lcc}
\hline & \multicolumn{2}{c}{ Degree of certainty $^{\mathrm{a}}$} \\
\cline { 2 - 3 } Form recognition & $\mathrm{M}$ & $\mathrm{SD}$ \\
Meaning recall & 2.75 & 0.97 \\
Meaning recognition & 2.42 & 1.00 \\
Collocation recall & 2.83 & 1.40 \\
Collocation recognition & 2.17 & 0.84 \\
& 3.17 & 0.84 \\
\hline
\end{tabular}

${ }^{\mathrm{a}} \mathrm{Max}=4$ (very certain); Min = 1 (very uncertain) 